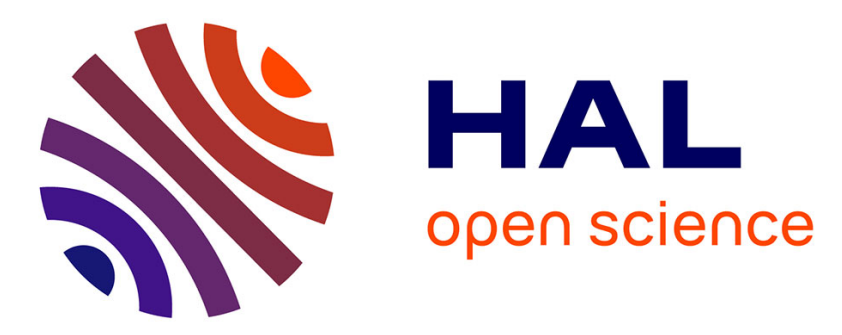

\title{
Adsorption and photophysical properties of fluorescent dyes over montmorillonite and saponite modified by surfactant
}

Vidhyadevy Tangaraj, Jean-Marc Janot, Maguy Jaber, Mikhael Bechelany, Sebastien Balme

\section{To cite this version:}

Vidhyadevy Tangaraj, Jean-Marc Janot, Maguy Jaber, Mikhael Bechelany, Sebastien Balme. Adsorption and photophysical properties of fluorescent dyes over montmorillonite and saponite modified by surfactant. Chemosphere, 2017, 184, pp.1355-1361. 10.1016/j.chemosphere.2017.06.126 . hal01552808

\section{HAL Id: hal-01552808 \\ https: / hal.sorbonne-universite.fr/hal-01552808}

Submitted on 3 Jul 2017

HAL is a multi-disciplinary open access archive for the deposit and dissemination of scientific research documents, whether they are published or not. The documents may come from teaching and research institutions in France or abroad, or from public or private research centers.
L'archive ouverte pluridisciplinaire HAL, est destinée au dépôt et à la diffusion de documents scientifiques de niveau recherche, publiés ou non, émanant des établissements d'enseignement et de recherche français ou étrangers, des laboratoires publics ou privés. 


\title{
Adsorption and photophysical properties of fluorescent dyes over
}

$$
\text { montmorillonite and saponite modified by surfactant }
$$

\author{
Vidhyadevy Tangaraj ${ }^{1}$, Jean-Marc Janot ${ }^{1}$, Maguy Jaber*2, Mikhael Bechelany ${ }^{1}$ and Sebastien \\ Balme $^{1 *}$ \\ ${ }^{1}$ Institut Européen des Membranes, UMR 5635, Université de Montpellier, ENSCM, CNRS, Place Eugène Bataillon, \\ F-34095 Montpellier cedex 5, France \\ ${ }^{2}$ Sorbonne Universités, UPMC Univ Paris 06, CNRS, UMR 8220, laboratoire d'archéologie moléculaire et \\ structurale (LAMS), Boîte courrier 225, 4 place Jussieu 75005 Paris, France \\ *Corresponding authors : sebastien.balme@umontpellier.fr and maguy.jaber@upmc.fr
}

\section{Abstract}

In the present study, the adsorption capacities of two intercalated smectites, CTAB-saponite and CTAB-montmorillonite with a cationic surfactant, were investigated with three fluorescent dyes namely Rhodamine 640 perchlorate rhodamine (Rho), sulforhodamine B (SR) and Kiton red 620 (KR). The adsorption isotherms fit well with the non-linear Langmuir isotherm model and the maximum adsorption capacities of all the composites are determined. The photophysical properties such as anisotropy and fluorescence lifetime of all the fluorescent dyes over the clay materials are determined. The set of experimental data based on X-Ray diffraction (XRD), transmission electron microscopy (TEM), Thermal analysis (TG-DTA) and fluorescence measurements allow highlighting the presence or the absence of interactions between the dyes and the modified clay minerals.

Keywords: montmorillonite, saponite, fluorescent dyes, adsorption isotherm, anisotropy 


\section{Introduction}

The adsorption of dyes have been Longley investigated on clay minerals $([1,2]$. The later have layered structure composed of octahedral and tetrahedral sheets consisting of fine particles

5 of size $<2 \mu \mathrm{m}$. Each tetrahedron consists of a cation, T, coordinated by four oxygen atoms and

6 linked to adjacent tetrahedral by sharing three corners (the basal oxygen atoms, Oxb) to form an

7 infinite two-dimensional 'hexagonal'. Each octahedron consists of a cation, O, coordinated by 8 six oxygen atoms and linked to neighboring octahedral by sharing edges. They have been 9 employed in several applications such as adsorbents, catalysts and host materials [3]. The surface properties of clay minerals were determined by the number of their active sites and the type of

11 their exchangeable inorganic cations present in the interlayer space, their composition, the 12 substitution ratio and its localization in the layers. These properties with the ability to swell in 13 water and presence of both Bronsted and Lewis acidity make the clays possible excellent host 14 materials for a wide range of organic and bio-molecules [4-8]. The Bronsted acidity is due to the 15 formation of $\mathrm{H}^{+}$ions on the surface by dissociation of hydrated exchangeable metal cations of 16 clays in water. This may also arise from a negative net charge on the surface by the substation of $17 \mathrm{Al}^{3+}$ instead of $\mathrm{Si}^{4+}$ at some tetrahedral positions and the net charge is balanced by $\mathrm{H}_{3} \mathrm{O}^{+}$cations. 18 Clays are acting as an electron acceptor in most of the electron transfer process and this Lewis 19 acidity character arises due to the external surface of the clay build-up of outer surface and lateral surface (edges). In these cases mostly $\mathrm{Al}^{3+}$ arising from rupture of $\mathrm{Si}-\mathrm{O}-\mathrm{Al}$ bond or $\mathrm{Al}^{3+}$ at

21 the edges, or through dehydroxylation of some Bronsted acid sites [9, 10]. The edges and the 22 faces of clay particles are responsible to adsorb cations, anions, nonionic and polar contaminants 23 from natural water. Adsorption of pollutants over the surface of clay may occur through ion 
1 exchange, ion-dipole interaction or coordination process from either strong or weak interactions

$2[11,12]$.

3 Industries are main source of water pollution and it produces toxic pollutants that are harmful to

4 humans, animals and water bodies. One of such important pollutant is dyes; colored compounds

5 are widely used in many industries such as textile, leather, pharmaceutical, paper, tanning, pulp

6 etc. Some of dyes are carcinogenic and not biodegradable $[13,14]$. Various physicochemical and

7 biological treatment methods have been reported to remove organic dyes from wastewater.

8 Adsorption is proven to be a practical way for the treatment of dye wastewater due to its

9 efficiency, selectivity and cost effective nature [15]. The modification of clay minerals with

10 organic molecules such as surfactant $[16,17]$ has been widely reported to increase the affinity of

11 these materials with organic pollutants [18-20].

12 Among different types of dyes, molecules of Xanthene family are commonly used for their

13 photophysical properties and have vast applications in sensors based thin films, in biological

14 systems, in laser technology, in supramolecular chemistry etc. The three fluorescent dyes (Figure

15 1) namely rhodamine 640 (Rho), sulforhodamine 640 (SR) and Kiton red 620 (KR) are selected

16 for the current study due to their very good quantum efficiency and their photochemical stability.

17 The aim of the present work is to study the efficiency of different smectites in the adsorption of

18 three fluorescent dyes i.e. Rho, SR, and KR. The smectites used were synthetic sodium

19 montmorillonite (Na-Mt) and sodium Saponite (Na-Sap) and their equivalent modified with

20 cetyltrimethylammonium bromide, a cationic surfactant (CTAB). The dyes location has been

21 studied by XRD and TEM. The adsorption isotherms have been conducted to evaluate the

22 adsorption mechanism and to evaluate the adsorption capacities of the clays. The photophysical 
1 properties of the adsorbed dyes were investigated in aqueous solution by the time resolved

2 fluorescence and anisotropy of fluorescence.

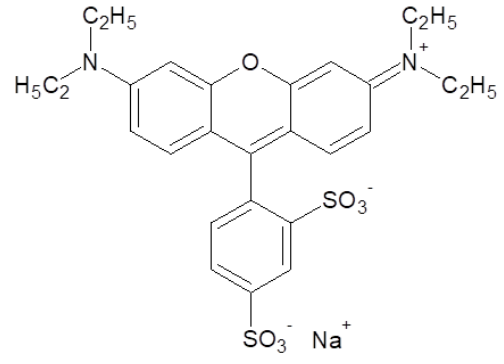

Kiton red $620(K R)$

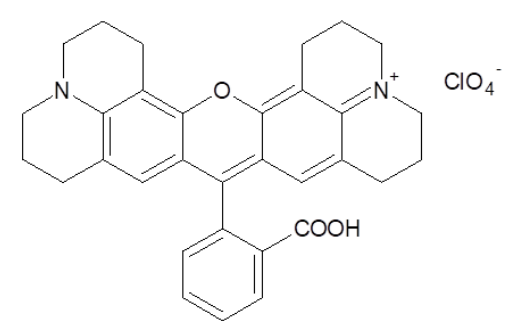

Rhodamine 640 (Rho)

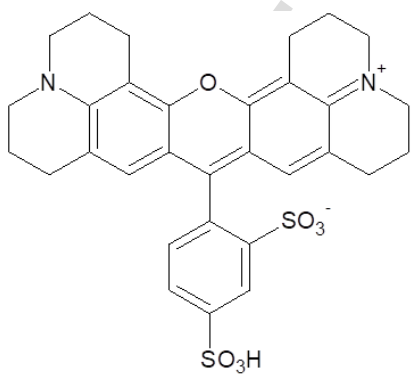

Sulforhodamine 640(SR)
3

4

5

6

7

8

9

10

11

12

\section{Experimental section}

\subsection{Materials}

Figure 1 : Structure of dyes used in this study

Four different clays namely synthetic Montmorillonite (Na-Mt) and (CTAB-Mt), sodium Saponite (Na-Sap) and (CTAB-Sap) were used for the confinement of fluorescent dyes namely rhodamine 640 perchlorate (Rho), sulforhodamine 640 (SR) and Kiton Red 620 (KR) from aqueous solution. All dyes were purchased from Exciton.

\subsection{Preparation of clays}

Montmorillonite synthesis: Hydrofluoric acid (HF, 40\% w/w; Fluka), sodium acetate $\left(\mathrm{NaCOOCH}_{3}, 99 \%\right.$; Fluka), magnesium acetate $\left(\mathrm{Mg}\left(\mathrm{COOCH}_{3}\right)_{2} 4 \mathrm{H}_{2} \mathrm{O}, 99 \%\right.$; Fluka), boehmite $\left(\mathrm{Al}_{2} \mathrm{O}_{3}, 75278 \%\right.$, Pural SB1; Condea), and silica $\left(\mathrm{SiO}_{2}, 99.5 \%\right.$, Aerosil 130; Evonik) were used to prepare a hydrogel with the following chemical composition $1 \mathrm{SiO}_{2}: 0.15 \cdot \mathrm{Al}_{2} \mathrm{O}_{3}: 0.2 \cdot \mathrm{MgO}$ : 
$0.1 \cdot \mathrm{Na}_{2} \mathrm{O}: 0.05 \cdot \mathrm{HF}: 96 \cdot \mathrm{H}_{2} \mathrm{O}[21]$. The hydrogels were matured over a $2 \mathrm{~h}$ period at room temperature and then introduced into a PTFE-lined stainless steel autoclave. The autoclaves were heated at $200^{\circ} \mathrm{C}$ for $72 \mathrm{~h}$. After reaction, autoclaves were cooled to room temperature. Run products were then recovered by filtration, washed thoroughly with distilled water and dried at $60^{\circ} \mathrm{C}$ for $12 \mathrm{~h}$. The ideal formula per half unit cell is $\left.\mathrm{Na}_{0.2}\left(\mathrm{Si}_{4}\right)\left(\mathrm{Al}_{1.8} \mathrm{Mg}_{0.2}\right) \mathrm{O}_{10}(\mathrm{OH}, \mathrm{F})_{2}\right]$ with a theoretical octahedral substitution rate (i.e. the number of $\mathrm{Mg}^{2+}$ to $\mathrm{Al}^{3+}$ substitution per half-cell) of 0.2 , yielding a cation exchange capacity of 0.382 meq g-1 $^{-1}[22]$.

Saponite was synthesized according to a previously published procedure having the following chemical formula: $\left.\mathrm{Na}_{0.4}\left[\mathrm{Si}_{3.6} \mathrm{Al}_{0.4}\right)\left(\mathrm{Mg}_{3}\right) \mathrm{O}_{10}(\mathrm{OH}, \mathrm{F})_{2}\right]$. That is, the $\mathrm{Al}$ substitution rate expressed per full unit cell is $x=0.8$ [23]. Hydrofluoric acid (HF, $40 \% \mathrm{w} / \mathrm{w}$; Fluka), sodium acetate $\left(\mathrm{NaCOOCH}_{3}, 99 \%\right.$; Fluka), magnesium acetate $\left(\mathrm{Mg}\left(\mathrm{COOCH}_{3}\right)_{2} 4 \mathrm{H}_{2} \mathrm{O}, 99 \%\right.$; Fluka), aluminum basic diacetate (19\%, sigma aldrich), and silica $\left(\mathrm{SiO}_{2}, 99.5 \%\right.$, Aerosil 130; Evonik) were used to prepare a hydrogel with the following chemical composition $1 \mathrm{SiO}_{2}: 0.15 \cdot \mathrm{Al}_{2} \mathrm{O}_{3}: 0.2 \cdot \mathrm{MgO}$ : $0.1 \cdot \mathrm{Na}_{2} \mathrm{O}: 0.05 \cdot \mathrm{HF}: 96 \cdot \mathrm{H}_{2} \mathrm{O}$. The hydrogels were matured over a $2 \mathrm{~h}$ period at room temperature and then introduced into a PTFE-lined stainless steel autoclave. The autoclaves were heated at $200^{\circ} \mathrm{C}$ for $72 \mathrm{~h}$. After reaction, autoclaves were cooled to room temperature. Run products were then recovered by filtration, washed thoroughly with distilled water and dried at $60^{\circ} \mathrm{C}$ for $12 \mathrm{~h}$.

Cation-exchange Montmorillonite and saponite: Na-Mt or Na-Sap was exchanged with cetyltrimethylammonium bromide (CTAB). The clay mineral was added in a large amount of the surfactant solution $\left(0.1 \mathrm{~mol} \mathrm{~L}^{-1}\right)$ and kept under stirring. A ratio of $1.5 \mathrm{~g}$ of montmorillonite for $100 \mathrm{~mL}$ of solution was chosen. Three successive baths of increasing times were conducted 
under stirring, 1 hours, 3 hours, and 24 hours to perform a total cationic exchange. After the final bath of $24 \mathrm{~h}$, samples were recovered by centrifugation and five washing steps with distilled water. After filtration, the solid fraction was dried in an oven at $60^{\circ} \mathrm{C}$. The obtained materials are noted CTAB-Mt and CTAB-Sap.

\subsection{Dye adsorption on material}

The fluorescence dyes were adsorbed on the materials as follow: $2 \mathrm{mg}$ of clays was added to 2 $\mathrm{mL}$ of dye solution at the different concentration (from 0.25 to $8 \mathrm{mg} \mathrm{L}^{-1}$ ). The mixture was stirred for one hour at room temperature and then centrifuged to separate the adsorbent. The concentration of dye in supernatant was analyzed using UV- visible spectrophotometer (JASCO). The dye concentration was obtained from the absorbance at $566 \mathrm{~nm}$ for Kiton Red 620, $574 \mathrm{~nm}$ for rhodamine 640 and $586 \mathrm{~nm}$ for sulforhodamine 640 .

\subsection{Instrumental methods}

All the samples were characterized by Fourier Thermogravimetric Analysis (TGA) using TA instruments TGA G500 under oxygen flow of $60 \mathrm{~mL} \mathrm{~min}^{-1}$. The samples were heated up to 700 ${ }^{\circ} \mathrm{C}$ at a heating rate of $10{ }^{\circ} \mathrm{C} \mathrm{min}^{-1}$ and equilibrated for 60 minutes at $700{ }^{\circ} \mathrm{C}$ for complete degradation of organic molecules. X-ray diffraction (PANAlyticalXpert-PRO diffractometer equipped with aX'celerator detector using Ni-filtered Cu-radiation) were recorded using $\mathrm{Cu}$ $\mathrm{K}_{\alpha}(\lambda=1.5418 \AA)$ radiation at $40 \mathrm{kV}$ and $20 \mathrm{~mA}$ and secondary monochromator in the $2 \Theta$ range of $3-70^{\circ}$ with a scan speed of $2^{\circ} \min ^{-1}$. Transmission electron microscopy (TEM) study of the samples was performed on a JEOL100CX microscope. Samples in the form of bulk powders were suspended in ethanol and then deposited on 400 mesh copper grids covered with an ultrathin carbon membrane of 2-3 nm thickness. 


\section{Time resolved fluorescence analysis}

For Fluorescence experiments, $2 \mathrm{~mL}$ of the $10 \mathrm{mg} \mathrm{L}^{-1}$ of each fluorescent dye solution was mixed with $2 \mathrm{mg}$ of clays. The mixture was stirred and analyzed after one hour using fluorimeters. The steady-state fluorescence were recorded by fluorescence spectrophotometer Spex (Fluorolog 1681) at a scanning rate of $1 \mathrm{~nm} \mathrm{~s}^{-1}$. Time-resolved fluorescence data were obtained by the time-correlated single-photon counting technique[24, 25]. The excitation wavelength was achieved by using a SuperK Extrem high power white supercontinum laser (NTK Photonics, model EXR-15) as a continuum pulsed source. The wavelength was selected by coupling to a monochromator (Jobin-Yvon H10). The repetition rate was set to $38.9 \mathrm{MHz}$; the excitation pulse duration on this device is around 6 ps (full-width-at-half-maximum, FWHM). The emission of fluorescence is detected, after passing through a polarizer oriented parallel, perpendicular or at the magic angle $\left(54.73^{\circ}\right)$ to polarization of excitation, through a double monochromator Jobin-Yvon DH10 on a hybrid PMT detector HPM-100-40 (Becker \&Hickl). The instrumental response function of the equipment was measured by using a dilute suspension of polystyrene nanospheres in water (70 $\mathrm{nm}$ of diameter) as a scattering solution; it was typically about 130-160 ps FWHM. Decays were collected at a maximum count rate of $15 \mathrm{kHz}$ into 4096 channels using an acquisition card SPC-730(Becker \& Hickl). This limiting count rate was achieved by dilution of the sample and after sedimentation of the suspension in order to minimize as much as possible the scattering of the particles. The time per channel was set around $6 \mathrm{ps} \mathrm{ch}^{-1}$ in order to fit a full decay in the experimental time window. All decays were collected so as to have at least $1.510^{6}$ counts in total. Decay analysis was performed using a LevenbergMarquardt algorithm. For the analysis, the fluorescence decay law at the magic angle $I_{M}(t)$ were 
1 assumed as a sum of exponentials. Fluorescence lifetimes were calculated from data collected at

2 magic angle by iterative adjustment after convolution of a pump profile (scattered light) with a

3 sum of exponentials. We assumed a Poisson distribution of counts in the calculation of the $\chi^{2}$

4 criterion; residuals profiles and autocorrelation function as well as Durbin-Watson and skewness

5 factor were used in order to estimate the quality of the adjustment. The number of exponentials

6 used for the fit was increased until all the statistical criterions were improved.

\section{3. Results and discussion}

\section{3.1. TGA Analysis}

10 The thermal stability of all the samples is shown in Figure 2a. Results show that unmodified

11 clays such as Na-Mt and Na-Sap undergo three stages of degradation. The first stage involves a

12 weight loss of $6-9 \%$ in the temperature range of $45-70^{\circ} \mathrm{C}$, which is due to the evaporation of

13 the physisorbed water. The second stage of degradation is assumed to be dehydration of the

14 hydrated cation in the interlayer at the temperature range of $80-150^{\circ} \mathrm{C}$ with a weight loss of 15

$15 \%$. A weight loss of $3 \%$ for Na-Mt and $0.2 \%$ for Na-Sap occurs in the third stage, in the 16 temperature range of $450-650^{\circ} \mathrm{C}$, which is due to the dehydroxylation of the corresponding clays. 

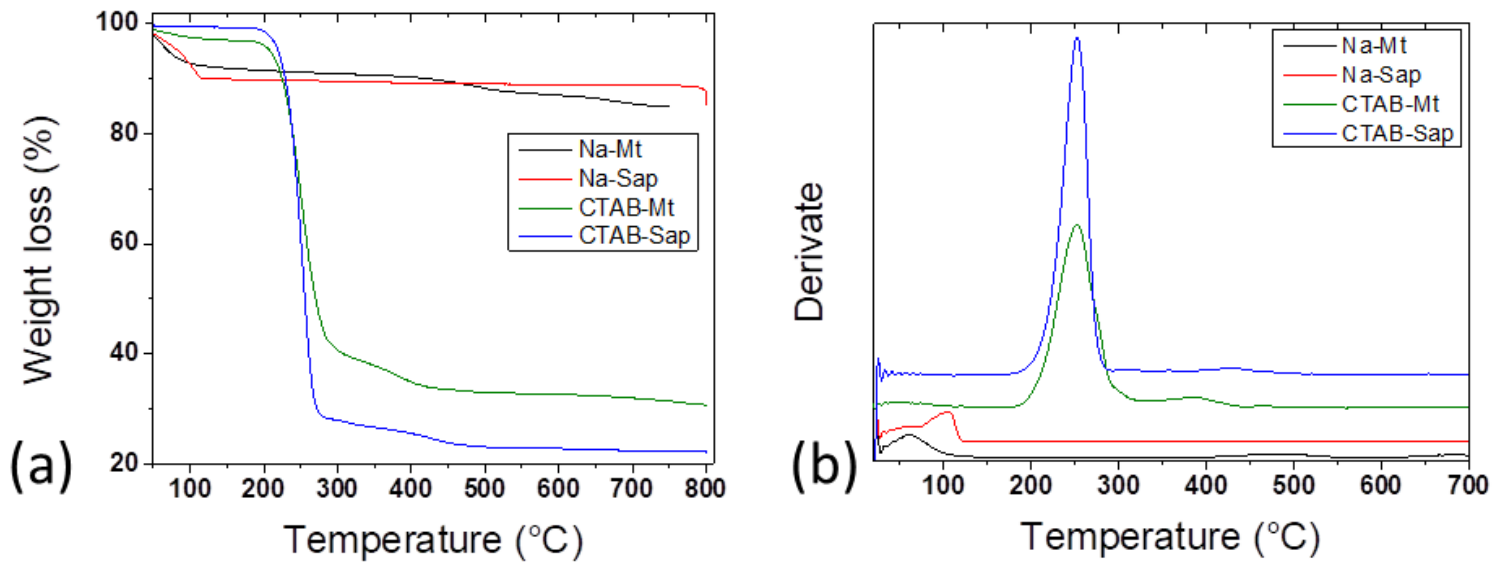

Figure 2 : a) TGA curves of raw Na-Mt, Na-Sap, CTAB-Mt and CTAB-Sap and b) DTG curves of raw Na-Mt, Na-Sap, CTAB-Mt and CTAB-Sap.

6 The DTG curves (Figure 2b) of CTAB-Mt and CTAB-Sap samples show the peaks of

7 montmorillonite and saponite plus some specific signals with maxima at about 240 and $400{ }^{\circ} \mathrm{C}$,

8 which are assigned to the progressive elimination of the organic matter. The first degradation is

9 attributed to the loss of water and solvent from the ambient to $190-200^{\circ} \mathrm{C}$ temperature range. The

10 second step is from $190^{\circ} \mathrm{C}$ to $275^{\circ} \mathrm{C}$ and is due to the loss of hydration water from the $\mathrm{Na}^{+}$ion. In

11 the third degradation step, at the temperature at around $410^{\circ} \mathrm{C}$ is assumed to be the surfactant

12 removal. The loss structure of the hydroxyl group within the clay is occurred at the final

13 degradation step in the TGA curves at around $540^{\circ} \mathrm{C}$. This result confirms the thermal stability of

14 modified montmorillonite and saponite clays by surfactant previously reported elsewhere [26, $1527]$.

16

17 3.2. XRD analysis 
1 XRD patterns (Figure 3) of synthetic montmorillonite and saponite exhibit typical $h k l$ bands of

2 smectites $[28,29]$. The (001) reflexion shows an inter-reticular distance of $1.26 \mathrm{~nm}$, typical of

3 the "one-water layer" form. The $\mathrm{d}(060)$ of the Mt is equal to $0.149 \mathrm{~nm}$ typical of dioctahedral

4 character while the one of saponite is equal to $0.152 \mathrm{~nm}$ characteristic of trioctahedral character.

5 The direct adsorption of the dye on the Na-Sap clay mineral does not induce any change. On the

6 opposite, for Na-Mt, the d(001) disappeared after SR adsorption. This should be explained by a

7 disordered stacking of the Mt layers. After exchange with the cationic surfactant, the $\mathrm{d}_{001}$ value

8 increases until $2.26 \mathrm{~nm}$ and $2.5 \mathrm{~nm}$, indicating the intercalation of the later in the interlayer space

9 of Mt and Sap, respectively. The adsorption of the anionic dye induce the disappearance of the

10 peak at $3.5^{\circ}(2 \theta)$ in the case of CTAB-Mt which can correspond to the desorption of the cationic

11 surfactant by the dyes. In the case of CTAB-Sap sample, does not show any modification on the

12 XRD pattern for both CTAB-Mt and CTAB-Sap. The XRD of the SR-CTAB-Sap does not

13 exhibit any peaks in the region $2-10^{\circ}(2 \theta)$ due probably to a partial exfoliation or a heterogeneity

14 in the layers stacking.
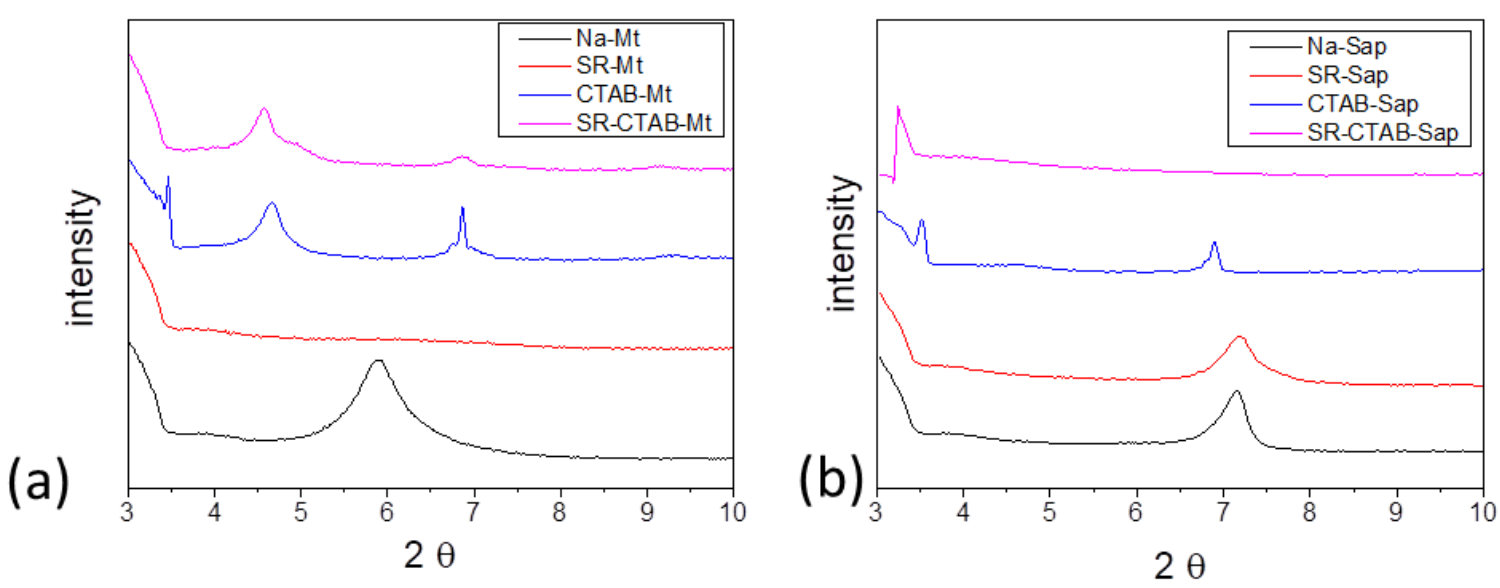


\section{$2 \quad 3.3$. TEM experiments}

3 Transmission electron microscopy (TEM) micrographs show layered structures with alternate

4 dark and bright fringes with a repeat length of $1.2 \mathrm{~nm}$ for the raw Mt. After Sr adsorption, an

5 heterogeneity in the stacking of the layers is observed confirming the absence of the (001)

6 reflexion in the XRD pattern. In the CTAB-Mt samples, a distance of $2.2 \mathrm{~nm}$ (Figure 4) is

7 measured. For and SR-CTAB-Sap samples, TEM micrographs exhibit an heterogeneity in the

8 layer stacking explaining the absence of (001) reflexion in the XRD patterns: indeed images

9 show some exfoliated layers and others intercalated with organic molecules with a d(001)

10 spacing of $2.5 \mathrm{~nm}$. (Figure 4). 

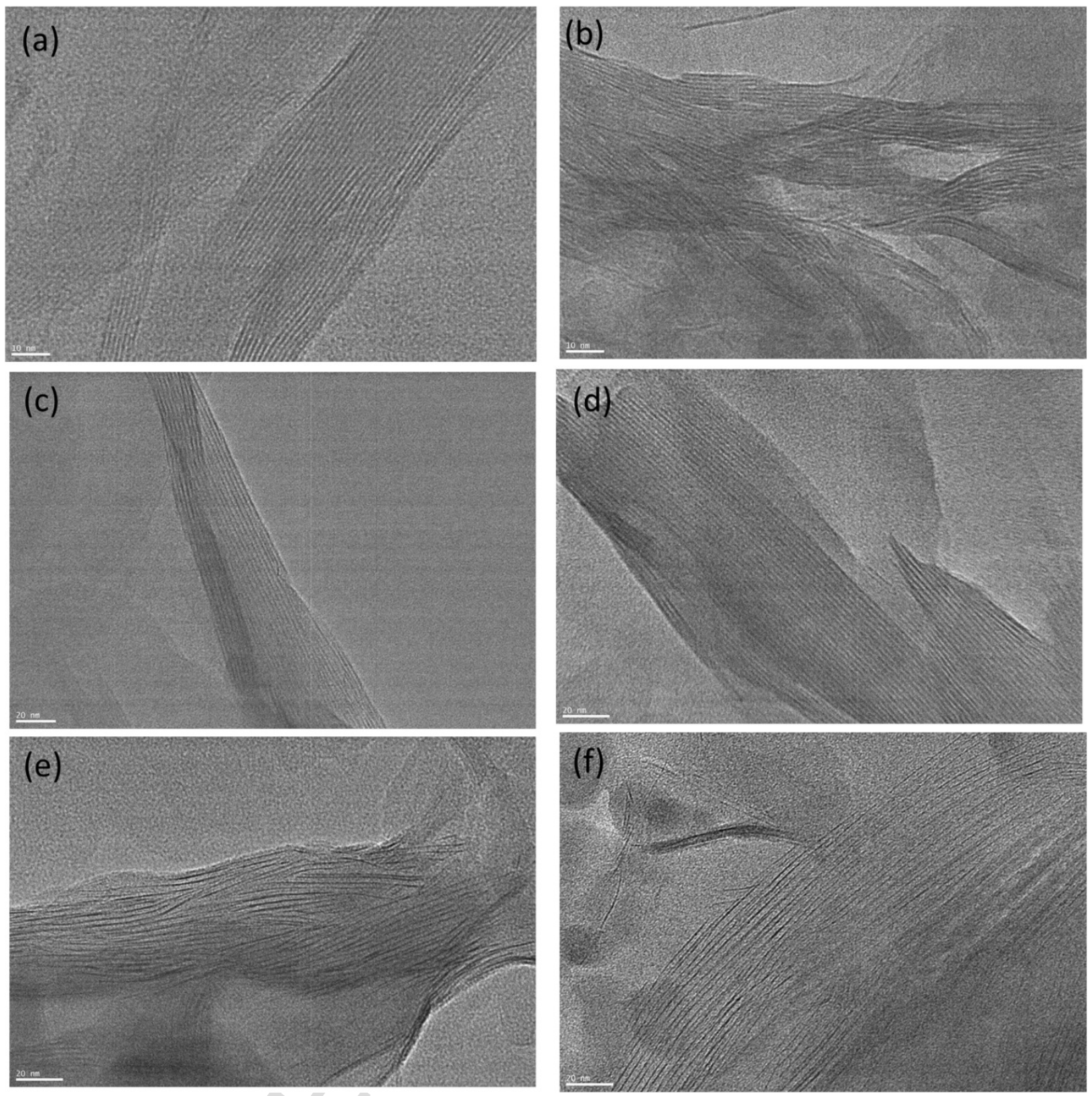

Figure 4 : TEM micrograph of raw Na-Mt (a), SR-Mt (b), SR-CTAB-Mt (c-d) and for SR-CTAB-Sap (e-f)

3

$4 \quad$ 3.4. Isotherm studies

Adsorption isotherm models play an important role in the determination of the maximum

6 capacity of adsorption, and clearly depict the relationship of the amount of dyes adsorbed by a

7 unit weight of the clays at equilibrium. The equilibrium adsorption isotherm explains how the 
1 dye interacts with the clay, and how the adsorbate distributes between the solution $\left(C_{e}\right)$ and the

2 solid phase $\left(q_{e}\right)$ when the adsorption process reaches the equilibrium state. Adsorption isotherm

3 models such as Langmuir [30] and Freundlich [31] were commonly used to describe the

4 experimental data [32].

5 The Langmuir adsorption isotherm is based on the assumption that the monolayer adsorption

6 onto a surface containing a finite number of adsorption sites. It also assumes uniform energies of

7 adsorption as well as no mutual interaction between the adsorbed molecules. The non-linear

8 equation of the Langmuir isotherm model is expressed by equation 1:

$9 \quad \mathbf{q}_{\mathbf{e}}=\frac{\mathbf{q}_{\mathrm{m}} \mathbf{k}_{\mathrm{L}} \mathbf{C}_{\mathrm{e}}}{1+\mathbf{k}_{\mathrm{L}} \mathbf{C}_{\mathrm{e}}}$

10 where $q_{m}$ is the maximum monolayer adsorption capacity, $K_{L}$ the Langmuir equilibrium constant.

11 The essential characteristics of the Langmuir isotherm parameters can be expressed in terms of a

12 dimensionless constant called the separation factor, or a dimensionless equilibrium parameter,

13 " $\mathrm{R}_{\mathrm{L}}$ "[33]. The dimensionless constant $R_{L}$ is the essential characteristic of the Langmuir isotherm

14 and it can be expressed by equation 2

$15 \quad \mathbf{R}_{\mathbf{L}}=\frac{\mathbf{1}}{\mathbf{1}+\mathbf{k}_{\mathbf{L}} \mathbf{C}_{\mathbf{o}}}$

16 The Freundlich isotherm is based on the assumption that adsorption occurs on a heterogeneous

17 adsorption surface with different energies of adsorption and is given by the equation 3 .

$18 \quad \mathbf{q}_{\mathrm{e}}=\mathbf{K}_{\mathbf{f}} \cdot \mathbf{C}_{\mathbf{e}}^{\mathbf{1 / n}}$

19 where $K_{f}$ and $n$ are the Freundlich constants related to the adsorption capacity and adsorption

20 intensity respectively. The value of $1 / n$ that varies between 0.1 to 1.0 indicates the favorable

21 adsorption of molecule. $n$ is a measure of the deviation of the adsorption isotherm linearity. 

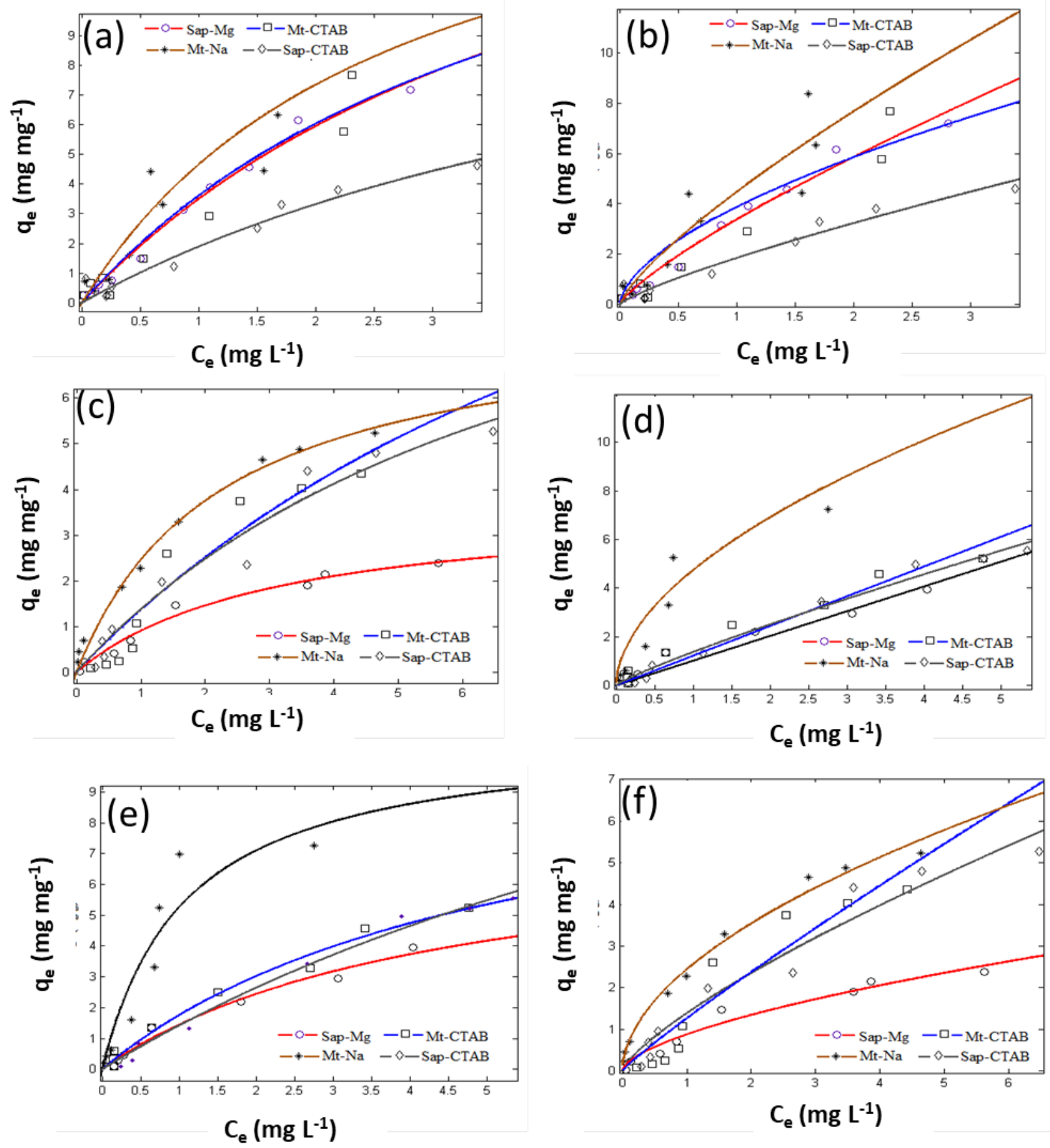

Figure 5 : Adsorption isotherm of KR (a-b), SR (c-d) and Rho (e-f) onto Na-Sap, Na-Mt, CTAB-Sap and CTAB-Mt. The open symbols are the experimental points. The lines are the nonlinear fit using Langmuir (a-c-e) and Freundlich (b-d-f) model

4 The experimental data $\left(q_{e}\right.$ and $C_{e}$ ) were fitted to above isotherm models using MATLAB 7.1 on

5 the effect of an initial concentration of Rho, SR and KR ions on the clays, and the graphical 
1 representations of these models are presented in Figures 5. The results are reported on Table 1

2 and 2 for Langmuir and Freundlich model respectively.

\begin{tabular}{|c|c|c|c|c|c|}
\hline \multicolumn{2}{|c|}{ CLAYS } & Na-Mt & CTAB-Mt & Na-Sap & CTAB-Sap \\
\hline \multirow{4}{*}{ KR } & $K_{L}\left(\mathrm{~L} \mathrm{mg}^{-1}\right)$ & 0.385 & 0.245 & 0.214 & 0.093 \\
\cline { 2 - 6 } & $q_{m}\left(\mathrm{mg} \mathrm{g}^{-1}\right)$ & 17.29 & 18.42 & 19.90 & 13.46 \\
\cline { 2 - 6 } & $R_{L}$ & $0.24-0.91$ & 0.82 & $0.84-0.88$ & 0.92 \\
\cline { 2 - 6 } & $\mathrm{R}^{2}$ & 0.804 & 0.925 & 0.988 & 0.818 \\
\hline \multirow{4}{*}{ SR } & $K_{L}\left(\mathrm{~L} \mathrm{mg}^{-1}\right)$ & 0.925 & 0.190 & 0.116 & 0.375 \\
\cline { 2 - 6 } & $q_{m}\left(\mathrm{mg} \mathrm{g}^{-1}\right)$ & 10.93 & 10.97 & 12.58 & 19.21 \\
\cline { 2 - 6 } & $R_{L}$ & $0.81-0.12$ & 0.85 & $0.89-0.9$ & 0.75 \\
\cline { 2 - 6 } & $\mathrm{R}^{2}$ & 0.893 & 0.984 & 0.981 & 0.978 \\
\hline \multirow{4}{*}{ Rho } & $K_{L}\left(\mathrm{~L} \mathrm{mg}^{-1}\right)$ & 0.977 & 0.128 & 0.071 & 0.010 \\
\cline { 2 - 6 } & $q_{m}\left(\mathrm{mg} \mathrm{g}^{-1}\right)$ & 7.93 & 8.78 & 16.78 & 12.22 \\
\cline { 2 - 6 } & $R_{L}$ & $0.8-0.11$ & 0.89 & $0.93-0.95$ & 0.99 \\
\cline { 2 - 6 } & $\mathrm{R}^{2}$ & 0.975 & 0.824 & 0.945 & 0.943 \\
\hline
\end{tabular}

Table 1 : Langmuir Isotherm Parameters for the adsorption of KR, SR AND Rho over clays

5 The dye adsorption on clay with or without surfactant can be roughly described by Langmuir isotherm following the value of $\mathrm{R}^{2}$. It seems that the presence of CTAB has not clear influence

7 on $q_{m}$. However it decreases the Langmuir constant affinity for Rho and KR. For SR, the results suggest a better affinity with CTAB exchanged samples in the case of Sap. The calculated $R_{L}$

9 values based on the Langmuir adsorption isotherm are close to 1 in a adsorption capacity $q_{m}$ 10 range of 8 to $20 \mathrm{mg} \mathrm{g}^{-1}$, indicating that the adsorption process is not strongly favorable. The 11 values of adsorption capacity are lower than the one reported for rhodamine $6 \mathrm{G} 38.21 \mathrm{mg} \mathrm{g}^{-1}$ 12 [34]. This should be explained by the ability to the rhodamine $\mathrm{G}$ for form dimer [35]. 
1 Freundlich parameter $n$ value indicates the degree of non-linearity between the solution

2 concentration and adsorption as follows: When $\underline{n}=1$, adsorption is linear, adsorption sites are

3 homogeneous in nature, no further adsorption takes place at the same site; when $\mathrm{n}<1$,

4 adsorbates are bound with weaker energies with adsorption sites. On the contrary, when $\mathrm{n}>1$,

5 more adsorbates are present in the solution enhances free energies for further adsorption. In the

6 present study, the value of $n$ was greater than 1 for all samples, which indicates the non-linear

7 heterogeneous adsorption of KR, SR, Rho.

\begin{tabular}{|c|c|c|c|c|c|}
\hline \multicolumn{2}{|c|}{ CLAYS } & Na-Mt & CTAB-Mt & Na-Sap & CTAB-Sap \\
\hline \multirow{3}{*}{ KR } & $K_{f}\left(\mathrm{mg} \mathrm{g}^{-1}\right)$ & 1.851 & 3.881 & 3.381 & 1.841 \\
\cline { 2 - 6 } & $n$ & 4.242 & 4.678 & 4.561 & 3.242 \\
\cline { 2 - 6 } & $\mathrm{R}^{2}$ & 0.8314 & 0.8655 & 0.9792 & 0.9485 \\
\hline SR & $K_{f}\left(\mathrm{mg} \mathrm{g}^{-1}\right)$ & 3.739 & 3.726 & 4.166 & 4.879 \\
\cline { 2 - 6 } & $n$ & 1.837 & 3.047 & 2.846 & 1.156 \\
\cline { 2 - 6 } & & 0.8003 & 0.935 & 0.945 & 0.9825 \\
\hline \multirow{2}{*}{ Rho } & $K_{f}\left(\mathrm{mg} \mathrm{g}^{-1}\right)$ & 2.114 & 2.966 & 4.8825 & 3.389 \\
\cline { 2 - 6 } & $n$ & 1.863 & 1.103 & 3.639 & 2.317 \\
\cline { 2 - 6 } & & 0.991 & 0.896 & 0.965 & 0.951 \\
\hline
\end{tabular}

Table 2 : Freundlich Isotherm Parameters for the adsorption of KR, SR and Rho over clays

\subsection{Impact of clays on photophysical properties of fluorescent dyes}

11 The photophysical properties of the different clay samples were studied by time resolved

12 fluorescence in aqueous solution. The fluorescence decay was reported in Figure 6 and the

13 results are summarized in Table 3. For KR, SR and Rho in water solution, the decay is fitted by 
monoexponential function with a lifetime $\tau^{K R}=1.58 \mathrm{~ns}, \tau^{S R}=4 \mathrm{~ns}$ and $\tau^{R H O}=4.1 \mathrm{~ns}$ respectively.

These three dyes have a close chemical structure which explains the similar lifetime for SR and Rho. The shorter lifetime for KR is usually explained by the dimer structure. When dyes are adsorbed on the different clays the fluorescence decay fit required two or three exponential components. For Rho, the long lifetime around 4 ns represents more than $90 \%$ yield whatever the clay. This suggests that the dye is surrounded by water molecules and thus not adsorbed on the clay surface. This is confirmed by the correlation time which is the same than the one for Rho free in solution. The second lifetime is shorter from 0.85 to $1.5 \mathrm{~ns}$ and depends on the clay sample. Indeed it is longer for sample exchange with CTAB than the one exchange with $\mathrm{Na}^{+}$or $\mathrm{Mg}^{+}$. This second lifetime could be assigned to the low amount of dye adsorbed on the material. The SR follows a similar behavior that Rho: (i) two lifetimes are required to fit the fluorescence decay, (ii) the long lifetime is the one than the dye in solution and (iii) the short lifetime is longer for clay exchange with $\mathrm{CTAB}$. However in the latter case, the yields of the short lifetime are $18 \%$ and $36.4 \%$ while less than $5 \%$ for the Rho. This could be explained by the better affinity of SR for CTAB modified clay than Rho which is in good agreement with the adsorption isotherm results (Table 1-2). The fluorescence decay of adsorbed KR require also 2 lifetimes one around $3.5 \mathrm{~ns}$ and one around $1.5 \mathrm{~ns}$. As the other sample, the correlation reveals that most of dye molecules are free in water solution. As previously mentioned, the KR is in dimer form which explains the short lifetime around $1.5 \mathrm{~ns}$. The lifetime around $3.5 \mathrm{~ns}$ could be assigned to KR monomer in water solution. This means that after adsorption, the clay permits a release of KR monomer. The separation of monomer is more efficient for Na-Sap and CTAB exchanged clay than for Na-Mt. Compare to the SR and Rho, the correlation with the affinity and the yield of short lifetime cannot be done. Indeed, the populations as dimer in solution than the one adsorbed 
1 on clay cannot be separated. Globally the fluorescence lifetime experiments permit to show the

2 release of fluorescence dye. This is in good agreement with the low affinity between the clay and

3 the dye as well as the location of dye at the surface of grain.

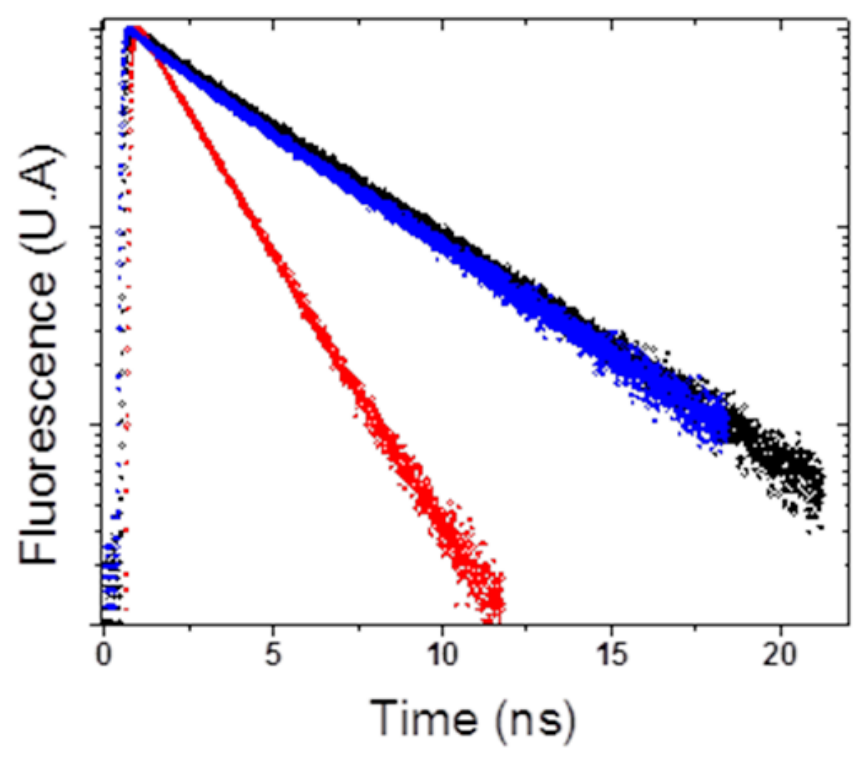

Figure 6: Examples of fluorescent decay $\mathrm{Kr}$ (red), SR (Blue) and Rho (black) loaded on Na-Mt

\begin{tabular}{|c|c|c|c|c|c|}
\hline CLAYS & & $\tau_{1}($ Yield $)(\mathrm{ns})$ & $\tau_{2}(\mathrm{~ns})($ Yield) & $\tau_{3}(\mathrm{~ns})($ Yield) & $\chi^{2}$ \\
\hline \multirow[t]{5}{*}{ KR (620 nm) } & Free & $1.58(100 \%)$ & & & \\
\hline & Mt-Na & $3.69(25.4 \%)$ & $1.58(74.6 \%)$ & & 1.16 \\
\hline & Sap-Na & $3.95(72.4 \%)$ & $1.66(21.0 \%)$ & $0.92(6.6 \%)$ & 1.09 \\
\hline & Mt-CTAB & $2.74(70 \%)$ & $1.54(28.3 \%)$ & $0.3(1.7 \%)$ & 1.11 \\
\hline & Sap-CTAB & $3.05(58.7 \%)$ & $1.82(41.3 \%)$ & & 1.06 \\
\hline \multirow[t]{4}{*}{ SR (610 nm) } & Free & $4(100)$ & & & \\
\hline & Mt-Na & $3.87(92.8)$ & $1.06(7.2 \%)$ & & 1.05 \\
\hline & Sap-Na & $4.04(99.2 \%)$ & $1.49(0.8 \%)$ & & 1.03 \\
\hline & Mt-CTAB & $2.99(52.2 \%)$ & $1.86(36.4 \%)$ & $1.06(8.4 \%)$ & 1.07 \\
\hline
\end{tabular}




\begin{tabular}{|l|l|l|l|l|l|}
\hline \multirow{2}{*}{ Rho (610 nm) } & Sap-CTAB & $3.36(82 \%)$ & $1.72(18 \%)$ & 1.02 \\
\cline { 2 - 6 } & Free & $4.1(100 \%)$ & & & \\
\cline { 2 - 6 } & Mt-Na & $3.99(98.2 \%)$ & $0.85(1.8 \%)$ & & 1.08 \\
\cline { 2 - 6 } & Sap-Na & $3.83(95.8 \%)$ & $1.19(4.2 \%)$ & & 1.05 \\
\cline { 2 - 6 } & Mt-CTAB & $3.92(96.3 \%)$ & $1.5(3.7 \%)$ & & 1.09 \\
\cline { 2 - 6 } & Sap-CTAB & $3.99(100 \%)$ & & & 1.03 \\
\hline
\end{tabular}

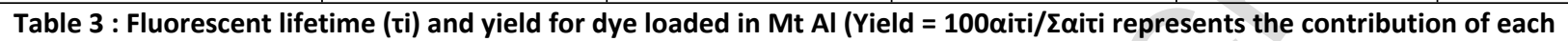
emission to the total emission)

\section{Conclusion} CTAB. Thermogravimetric analysis confirmed the presence of the organic matter in both clay minerals. The adsorption isotherm results showed that the affinity of dye is limited for interfacial concentration range from $7 \mathrm{mg} \mathrm{g}^{-1}$ to $20 \mathrm{mg} \mathrm{g}^{-1}$. The XRD patterns indicate an intercalation of the CTAB in the interlayer space. The presence of dyes does not affect the d001 value indicating that no intercalation occurred in interlayer space due probably to the low concentration of the dye in the material. The time resolved fluorescence of the adsorbed dyes show that most of the

12 dye molecules are released in solution. This is due likely to the poor affinity with the clay 13 minerals and the location at the grain surface. Interestingly in the case of KR which is usually in 14 dimer form in water, the adsorption on clay permits to release monomer in solution characterized 15 by a fluorescence lifetime around 3 ns. Regarding these results, we can conclude that the clay 16 could be interesting to dissociate this dye before using in water solution.

\section{Acknowledgement}


Commission for providing a fellowship for this research.

1. Thangaraj, V., et al., Fluorescence Quenching of Sulforhodamine Dye over Graphene Oxide and Boron Nitride Nanosheets. European Journal of Inorganic Chemistry, 2016(13-14): p. 2125-2130. Fournier, F., et al., Physico-chemical characterization of lake pigments based on montmorillonite and carminic acid. Applied Clay Science, 2016.

3. Jaber, M., et al., Selectivities in Adsorption and Peptidic Condensation in the (Arginine and Glutamic Acid)/Montmorillonite Clay System. Journal of Physical Chemistry C, 2014. 118(44): p. 25447-25455.

4. Raha, S., et al., Photo-stability of rhodamine-B/montmorillonite nanopigments in polypropylene matrix. Applied Clay Science, 2009. 42(3-4): p. 661-666.

5. Tanabe, K., Solid acid and base catalysis In: Anderson, JR, Boudart, M.,(eds), Catalysis-science and technology, 1981, New York, Springer-Verlag.

6. Balme, S., et al., Structure, orientation and stability of lysozyme confined in layered materials. Soft Matter, 2013. 9(11): p. 3188-3196.

7. Jaber, M., J. Miehe-Brendle, and R. Le Dred, Mercaptopropyl Al-Mg phyllosilicate: Synthesis and characterization by XRD, IR, and NMR. Chemistry Letters, 2002(9): p. 954-955.

8. Lepoitevin, M., et al., BSA and lysozyme adsorption on homoionic montmorillonite: Influence of the interlayer cation. Applied Clay Science, 2014. 95: p. 396-402.

9. Wang, P., M. Cheng, and Z. Zhang, On different photodecomposition behaviors of rhodamine $B$ on laponite and montmorillonite clay under visible light irradiation. Journal of Saudi Chemical Society, 2014. 18(4): p. 308-316.

10. Pankasem, S. and J.K. Thomas, Reflectance spectroscopic studies of the cation radical and the triplet of pyrene on alumina. The Journal of Physical Chemistry, 1991. 95(18): p. 6990-6996.

11. Srinivasan, R., Advances in Application of Natural Clay and Its Composites in Removal of Biological, Organic, and Inorganic Contaminants from Drinking Water. Advances in Materials Science and Engineering, 2011.

12. El Adraa, K., et al., Cysteine-montmorillonite composites for heavy metal cation complexation: A combined experimental and theoretical study. Chemical Engineering Journal, 2017. 314: p. 406417.

13. Vidhyadevi, T., et al., Adsorption of Congo Red Dye over Pendent Chlorobenzylidine Rings Present on Polythioamide Resin: Kinetic and Equilibrium Studies. Separation Science and Technology, 2013. 48(10): p. 1450-1458.

14. Premkumar, M., et al., Kinetic and equilibrium studies on the biosorption of textile dyes onto Plantago ovata seeds. Korean Journal of Chemical Engineering, 2013. 30(6): p. 1248-1256.

15. Vidhyadevi, T., et al., Optimization of the process parameters for the removal of reactive yellow dye by the low cost Setaria verticillata carbon using response surface methodology: Thermodynamic, kinetic, and equilibrium studies. Environmental Progress \& Sustainable Energy, 2014. 33(3): p. 855-865. 
16. He, H.P., et al., Organoclays prepared from montmorillonites with different cation exchange capacity and surfactant configuration. Applied Clay Science, 2010. 48(1-2): p. 67-72.

17. Guegan, R., Intercalation of a Nonionic Surfactant (C1OE3) Bilayer into a Na-Montmorillonite Clay. Langmuir, 2010. 26(24): p. 19175-19180.

18. Nourmoradi, H., M. Nikaeen, and M. Khiadani, Removal of benzene, toluene, ethylbenzene and xylene (BTEX) from aqueous solutions by montmorillonite modified with nonionic surfactant: Equilibrium, kinetic and thermodynamic study. Chemical Engineering Journal, 2012. 191: p. 341348.

19. Sanchez-Martin, M.J., et al., Efficiency of different clay minerals modified with a cationic surfactant in the adsorption of pesticides: Influence of clay type and pesticide hydrophobicity. Applied Clay Science, 2006. 31(3-4): p. 216-228.

20. Klumpp, E., H. Heitmann, and M.J. Schwuger, Synergistic Effects between Cationic Surfactants and Organic Pollutants on Clay-Minerals. Colloids and Surfaces a-Physicochemical and Engineering Aspects, 1993. 78: p. 93-98.

21. Georgelin, T., et al., Inorganic Phosphate and Nucleotides on Silica Surface: Condensation, Dismutation, and Phosphorylation. Journal of Physical Chemistry C, 2013. 117(24): p. 1257912590.

22. Cornu, D., et al., Influence of acid-base properties of Mg-based catalysts in transesterification. Role of Magnesium Silicate Hydrate formation. Catalysis Science and Technology, 2017. 7: p. $1701-1712$.

23. Jaber, M. and J. Miehe-Brendle, Influence of the synthesis medium on the saponite crystallisation: formation mechanism in acidic and basic media. Comptes Rendus Chimie, 2005. 8(2): p. 229-234.

24. Balme, S., et al., Highly efficient fluorescent label unquenched by protein interaction to probe the avidin rotational motion. Journal of Photochemistry and Photobiology A: Chemistry, 2006. 184(1-2): p. 204-211.

25. O'Connor, D.V. and D. Phillips, Time Correlated Single Photon Counting. Academic Press, ed. A. Press1984, New-York: Academic Press.

26. Beall, G.W. and M. Goss, Self-assembly of organic molecules on montmorillonite. Applied Clay Science, 2004. 27(3-4): p. 179-186.

27. Xi, Y., et al., Modification of Wyoming Montmorillonite Surfaces Using a Cationic Surfactant. Langmuir, 2005. 21(19): p. 8675-8680.

28. El Adraa, K., et al., Adsorption of L-DOPA Intercalated in Hydrated Na-Saponite Clay: A Combined Experimental and Theoretical Study. Journal of Physical Chemistry C, 2012. 116(50): p. 2641426421.

29. Lambert, J.F., et al., A comparative study of the catalysis of peptide bond formation by oxide surfaces. Physical Chemistry Chemical Physics, 2013. 15(32): p. 13371-13380.

30. Langmuir, I., The Adsorption of Gases on Plane Surfaces of Glass, Mica and Platinum. Journal of the American Chemical Society, 1918. 40: p. 1361-1403.

31. Freundlich, H.M.F., Over the adsorption in solution. Journal of Physical Chemistry, 1906. 57: $\mathrm{p}$. 384-470.

32. Benetoli, L.O.D., et al., Adsorption of nucleic acid bases on clays: an investigation using Langmuir and Freundlich isotherms and FT-IR spectroscopy. Monatshefte Fur Chemie, 2008. 139(7): p. 753-761.

33. Vidhyadevi, T., et al., A study on the removal of heavy metals and anionic dyes from aqueous solution by amorphous polyamide resin containing chlorobenzalimine and thioamide as chelating groups. Korean Journal of Chemical Engineering, 2015. 32(4): p. 650-660. 
1 34. Selvam, P.P., et al., Removal of rhodamine $B$ from aqueous solution by adsorption onto sodium 2 montmorillonite. Journal of Hazardous Materials, 2008. 155(1-2): p. 39-44.

$335 . \quad K l i k a, Z$., et al., The rhodamine B intercalation of montmorillonite. Journal of Colloid and 4 Interface Science, 2004. 275(1): p. 243-250.

5 
Na-Mt and Na-Sap were prepared and exchange with cationic surfactant CTAB

The adsorption of Rhodamine, kiton red and sulforhodamine on these materials was studied

Whatever the material the fluorescent dyes are not located inside interlamellar space

The dyes are released in water as monomer even for the kiton red 